\title{
Correction to: Heat Treatment of Alloy 718 Made by Additive Manufacturing for Oil and Gas Applications
}

\author{
BEN SUTTON ${ }^{10},{ }^{1,4}$ ED HERDERICK, ${ }^{1}$ RAMGOPAL THODLA, ${ }^{2}$ \\ MAGNUS AHLFORS, ${ }^{3}$ and ANTONIO RAMIREZ ${ }^{1}$ \\ 1.-The Ohio State University, Columbus, OH 43221, USA. 2.-DNV GL, Dublin, OH 43017, USA. \\ 3.-Quintus Technologies LLC, Lewis Center, OH 43035, USA. 4.-e-mail: sutton.213@osu.edu
}

Correction to: JOM, Vol. 71, No. 3, 2019

https://doi.org/10.1007/s11837-018-03321-7

In the last paragraph of the section "SOLIDIFICATION AND THERMODYNAMIC SIMULATIONS", the authors would like to change the sentence "Although the solvus temperature for $\delta$ was not predicted here, it should be near the nonequilibrium solidus temperature as it forms during the terminal stages of solidification" to "Although the solvus temperature for Laves was not predicted here, it should be near the non-equilibrium solidus temperature as it forms during the terminal stages of solidification".

Publisher's Note Springer Nature remains neutral with regard to jurisdictional claims in published maps and institutional affiliations. 